e-ISSN: 2721-3013, p-ISSN: 2721-3005

DOI: https://doi.org/10.38035/jafm.v1i3

Received: 7 May 2020, Revised: 16 May 2020, Publish: 6 July 2020 https://creativecommons.org/licenses/by/4.0/

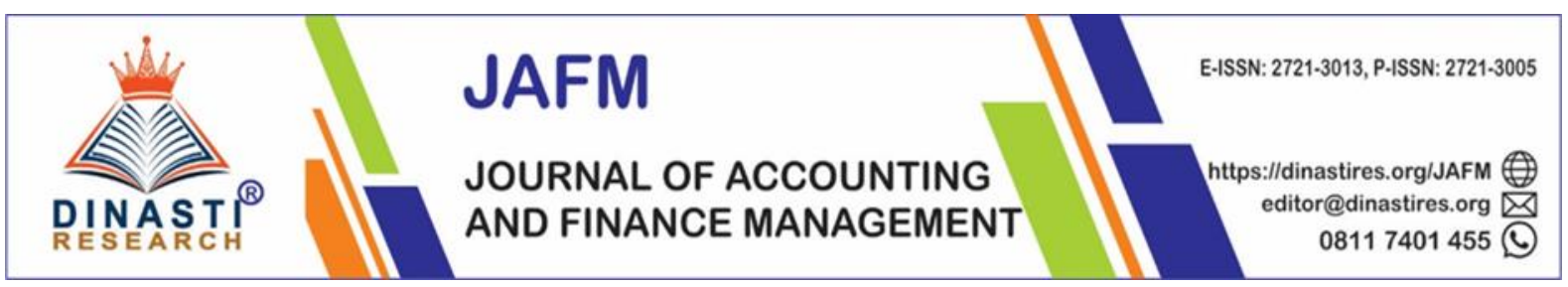

\title{
Design, Development and Implementation Sop with Service Blueprint, K Pharmacy in Surabaya
}

\author{
Yessica Anggraini Sutanto $^{1 *}$, Erna Andajani ${ }^{2}$ \\ ${ }^{1), 2)}$ University Surabaya, East Java, Indonesia, email: yessica.anggraini.sutanto@ gmail.com \\ *Corresponding author: Yessica Anggraini Sutanto ${ }^{1}$
}

\begin{abstract}
Background of this study is due to the absence Standard Operation Procedure (SOP) in K Pharmacy, can operational chaos. Solving these problems can be done by using the service blueprint, to find out the error process. This research not only designed, but also developed and implemented Standard Operation Procedure (SOP) and Service Blueprint. This type of research is applied research with descriptive qualitative methods. The technique of collecting data this study using purposive sampling technique. The methods collection data of this study were observation and depth interview. This research design used iterative process (exploration, creation, reflection and implementation). The result of this study are need to implement an electronic medical record system when doing assessments, implementing an inventory management system, providing a queue serial number of customers, and implementing an electronic cash register system.
\end{abstract}

Keywords: Service Development, Service Design, Service Blueprint, Standard Operation Procedure (SOP)

\section{INTRODUCTION}

Quality control is not only oriented to the results of goods and services, but rather on quality assurance standards (quality assurance). The measurement of quality is the service standard, useful as a guideline to implement and avoid mistakes in serving, explain the sequence or workflow, provide effective and efficient service processes, also manage consistency of service.

There were complaint about clinical pharmacy services at K Pharmacy, in suggestions boxes were made. And K Pharmacy not have Standard Operation Procedure (SOP) making this service inconsistent and long standing, so they need a system management for service. Making the SOP based on the Regulation of The Minister of Health RI No 73 of 2016, can be a tool to overcome problems K Pharmacy, provided idealizing the time and quality of service. Expectations on using SOP, can make service consistent and better. Implemented SOP need all participant understanding to involved services process to make satisfaction customer. 
The mapping of time service process can be clearly explained by using service blueprint. Stickdorn et. al. (2011) with University of Pittsburgh Medical Center (UPMC), used the service blueprint to mapping interactions between patients, staff, doctors, and other health workers, and became a guideline for making service blueprint K Pharmacy, which is a solution in understanding SOP to be made. Service blueprint is expected to provide a clear picture of the service design. It is also hoped that management can understand customer desires appropriately, meet customer expectations, both service time and service quality consistency. Service blueprint can identify errors in the service process. The identification of errors in the service process can reduce the risk of a process error in the service. K Pharmacy is designing a good pharmacy practice service process, for better service process improvement. This research more discuss how to making, improvement and implementation SOP and service blueprint pharmaceutical service at K Pharmacy. Also to find out error process (points failed) in service K Pharmacy.

\section{LITERATURE REVIEW}

The service design process begins with market research that explains in detail the needs of the community for a product or service. Service design will be useful if there is a target market share. Based on the research and available data, it is obtained the development of service design ideas on an ongoing basis. The idea can be in the form of a $2 \mathrm{D}$ sketch drawing concept or in a 3D virtual form, and various other fundamental concept forms. Technical components in the design concept must be able to be integrated with one another, as well as concepts that are not in accordance with the current conditions can be developed or changed in shape. The design concept can create service models, which are tested based on functionality, usability, production feasibility, cost and community response. If the trial results show positive results that are marketable, the product or service is ready to be produced further. Any mistakes in the production process will take a large amount of time and costs, and make a bad impact on the company. Based on this illustration of the exploration, creation, reflection design and implementation process, it is necessary to think through a mature approach in the design of new products and services. This is very important and determines subsequent success (Stickdorn et. al., 2011).

The process of exploration, creation, reflection design and implementation process can be called an iterative process. Iterative process is a fundamental approach in compiling complex service design processes (Stickdorn et al., 2011). In addition to the iterative process, there are various kinds of literature and research that have the same mindset and refer to various frameworks consisting of 3-7 steps or more (Best, 2006; Mager, 2009; Miettinen \& Koivisto, 2009). This research in making service design refers to iterative process.

Service blueprint is a special flowchart that maps the activities of customers and subscription providers. These activities are separated by lines of visibility, becoming the front part of the activity which is the first touch point with customers getting direct service experience (front office), to the process of behind the scenes activities that are outside the customer's view (back office). The front office is the visual part that deals with customers, including equipment, facilities, people, and services. The back office can organize design and operational support, including management, personnel (Gronroos, 1984; Zeithaml \& Bitner, 2009).

Service activities that have high or low touch points are mapped separately by a line of visibility, but are still connected with communication. This can shape customer perception regarding service effectiveness. Overall back office activities include the design process and have an indirect effect on customers. If an error occurs in this process it can result in a delay in the service process. Service blueprint is used in this study because it can describe the entire 
service process and detail every aspect. Service blueprint can also identify potential failures, so as to ensure the services provided are of high quality (Fitzsimmons \& Fitzsimmons, 2011).

Kingman-Brundage et.al. (1995) mapped the service blueprint design into 4 levels with 5 main activity scales and made the services oriented to certain things. Fitzsimmons \& Fitzsimmons (2011) argued that service blueprint can help organizations in identifying the entire service process, there are 5 components: physical evidence, customer actions, onstage contact person, backstage contact person, and support processes.

\section{METHODS}

Type of this research is applied research to find practical problem solving solutions. (Sekaran \& Bougie, 2016). In achieving research objectives, data collection is carried out with the aim of obtaining information or data that supports the research. The techniques data collection based on the subject of this study, using purposive sampling techniques. Purposive sampling as selecting research objects, and can help understand the phenomena that occur (Creswell, 2018). This research used methods collection data are observation and depth interviews. Observations were conducted on August 1 - 31, 2019. Depth interviews were given to 1 owner, 2 employees, 3 customers. The next step is to create and implement SPO and service blueprint for 3 months, from 2 September 2019 - 30 November 2019. After implementing SPO and service blueprint, the analysis of the evaluation results starts from 2 31 December 2019.

This case study research model redesigned the function of the clinical pharmacy service process in the $\mathrm{K}$ pharmacy, to making a quality management system with service blueprint. Service blueprint can be improvement in the order of services, creating a visual representation of the service improvement process by looking at the direction of the service flow diagram, and highlighting improvements or additional adjustments to the service flow. Service blueprint design uses iterative methods: exploration, creation, reflection and implementation.

\section{FINDINGS AND DISCUSSION Exploration}

After obtaining permission to conduct research, the first stage can be remapping analysis of the interaction of parties involved stakeholders and the surrounding environment, as well as discussing assumptions / ideas for the development of service design. Stakeholders involved are pharmacists, health technical personnel and customers. This personnel who are in charge and responsible for providing services at the K Pharmacy, are directly involved in the process of making and developing new service designs. It is also necessary to map out the vision, mission and job desk of the pharmacy management, so that all parties participate in understanding the duties and responsibilities of the K pharmacy service. Need to create a job description, do an evaluation and make adjustments to the current pharmacy environmental conditions. The evaluation results are consulted with the PSA and the supervisor. A detailed description of the duties and responsibilities of the PSA, APA, APING, and Pharmaceutical Technical / Cashier / Courier job desk, has been discussed in Chapter 3.

The division of tasks can clearly be identified in the initial problem by observing irregularities in the work flow of the pharmacy service delivery in the $\mathrm{K}$ pharmacy clinic which causes longer waiting times for services, at several meetings. Observation of clinical pharmacy services carried out for 2 weeks from 1 - 31 August 2019, aimed at understanding the problems of the K pharmacy and building relationships with pharmacists, health technical personnel, as well as customers.

After getting a clear problem, it is necessary to prioritize integrating the main problem with the real problem in the field. How to find out the main problems of the pharmacy in 
accordance with customer complaints, with making complaints boxes and suggestions can be one of the solutions to solve these problems. As well as to ascertain the existing problems, a clinical pharmacy service time was provided by the employees at the K Pharmacy directly and depth interviews with several respondents. The results of clinical pharmacy service observations and interview recap at the $\mathrm{K}$ pharmacy show the highest customer recommendation results are in complaints of long service time with a total of 14 suggestions (43\%). This is in accordance with customer complaints Untung "waiting drugs it's really long" After further investigation the service delivery time for each employee is different, some are fast and some are slow. Researchers also tried to calculate the service time of every 4 employees of the K pharmacy during August 1 - 15 2019. The average non-prescription service time was around 30 minutes 45 seconds. The fastest time is 11 minutes 7 seconds, and the longest time is around 44 minutes 12 seconds. Expectations from this study to equalize the non-prescription service time for each K pharmacy employee is less than 30 minutes. While the measurement of prescription service time is obtained an average time of about 1 hour 20 minutes 28 seconds. The fastest time is 57 minutes 21 seconds, and the longest time is around 1 hour 52 minutes 10 seconds. Expectations from this study to equalize prescription service time for each $\mathrm{K}$ pharmacy employee is less than 60 minutes.

Interviews were conducted in conjunction with research observations during $16-31$ August 2019, by giving open questions to 3 customers, 2 employees, and 1 owner of the K pharmacy facility. Open questions include the actual problems faced. Some interviews also have the same answers and can be summarized as one, and 1 respondent can produce several complaints. From interviews with 3 customers obtained 11 customer complaints. The highest complaint from the 3 customers was in the complaint about the service provided by the old $\mathrm{K}$ pharmacy employee and it was not clear with a percentage of $28 \%$. One of customers, when they finished redeeming the recipe, Hwie's said "the staff is turning from front to back, as well as serving others who want to buy it too, so it takes a long time to buy medicine." After reviewing the procedure, the $\mathrm{K}$ pharmacy does not have SPO of clinical pharmaceutical services, which can cause employees to not understand the flow of services, and work in their own way, so that the service time given to customers is long and unclear. This is in line with Rohma's statement "Yes because there are no standard procedures, so there are no standards of services, services depend on who is serving."

\section{Creation}

Flowchart can help visualize the interaction of service providers at each stage of the clinical pharmacy service experience at the K pharmacy, obtained in making 12 flowcharts and 12 SPOs. The SPO and flowchart improvements were carried out in the hope that it could help explain the service process at the K Pharmacy. The results of making the flowchart and SPO were consulted to the supervisor and owner of the pharmacy facility.

Service blueprint is used to visualize the interaction mapping between pharmacists, health technical personnel and especially focus on customer service and aims to avoid the risk of errors in the service process. The visualization maps customer interactions on the front stage that receives a variety of services (touch points), and is supported by systems and health technical personnel (backstage).

Mapping the service blueprint is an illustration of clinical pharmacy services at the $\mathrm{K}$ Pharmacy, especially looking at the customer's experience while waiting and not getting any interaction in service. This can be an opportunity to create and develop new service designs. From the 12 flowcharts, there were 2 flowcharts have a problem and showed the direct interaction between the customer and the customer provider in the K Pharmacy, so there were

2 types of service blueprints to be made, which is service blueprint for pharmaceutical 
/medical supplies without prescription and service blueprint for pharmaceutical/medical supplies with prescription.

Picture 1. Flowchart for pharmaceutical/medical supplies without prescription

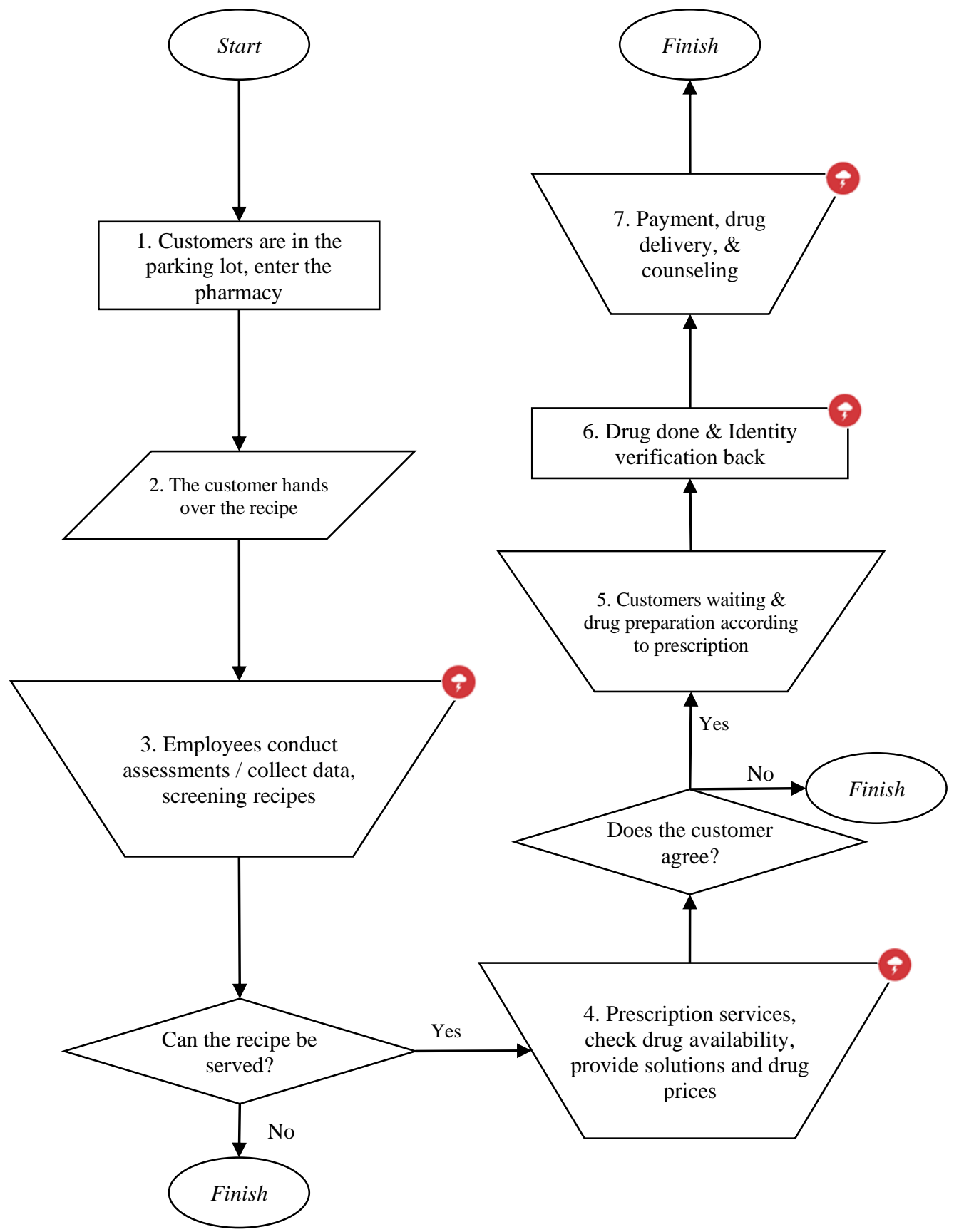

Picture 2. Flowchart for pharmaceutical/medical supplies with prescription 


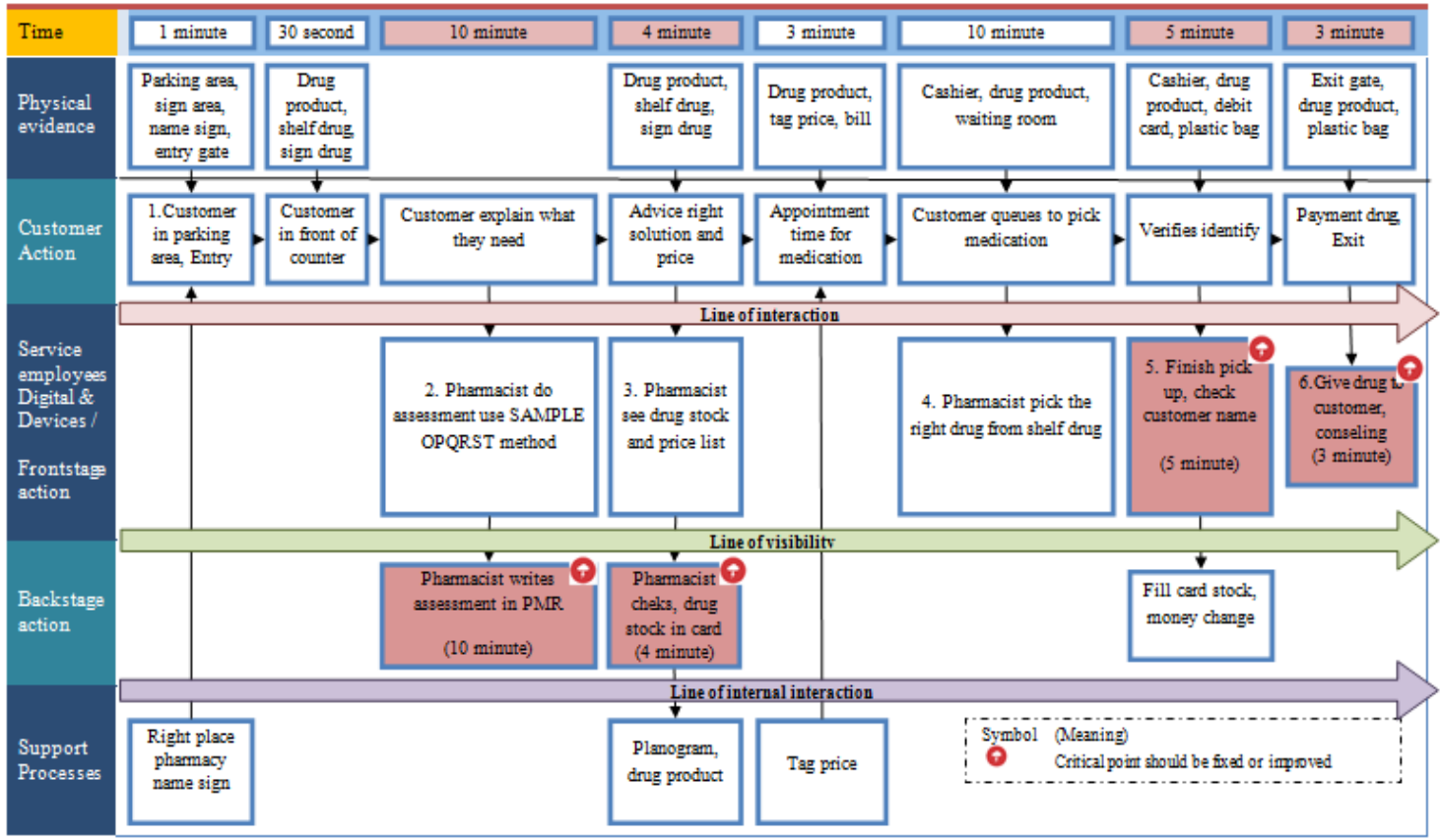

Picture 3. Service blueprint for pharmaceutical/medical supplies without prescription

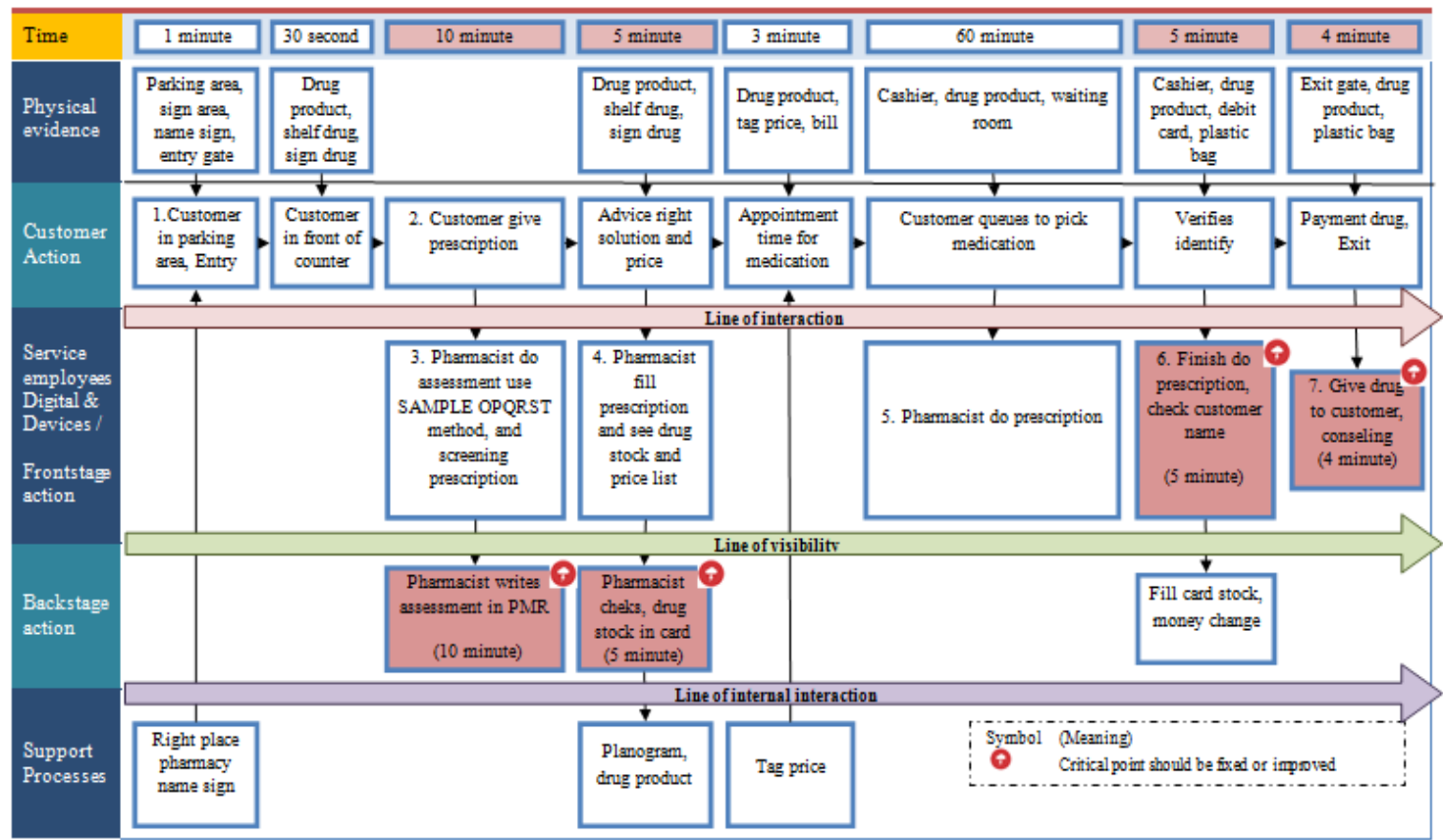

Picture 4. Service blueprint for pharmaceutical / medical supplies with prescription

\section{Reflection}

The next step can be an evaluation of the flowchart and service blueprint design review. The service blueprint of pharmaceutical and medical supplies without prescription and prescription has the same components: physical evidence with 7 points, customer action with 8 points, frontstage action with 5 points, backstage action with 3 points, and support processes with 3 points. This non-prescription pharmaceutical and medical service has an estimated duration of time \pm 36.5 minutes. Whereas the time points for prescription drug preparation showed a difference in time of about \pm 60 minutes, because the preparation of prescription drugs depends on the number, type, and items prescribed by the doctor.

After an evaluation, the development of the service blueprint for pharmaceutical and medical supplies without prescription was made, it was found that there was a streamlining of 
service time. The time the employee points to write the assessment in PMR becomes \pm 9 minutes, the time the employee points check the stock of drugs on the stock card to \pm 1 minute, the time the drug points are completed and the customer verification returns to \pm 1 minute, and the time of payment points, drug delivery, and counseling to \pm 2 minutes. This causes the preparation time of the drug to be \pm 14 minutes. From further observations of the service blueprint design, there are a number of points that require service improvement and development:

\section{Employee points write assessment in Patient Medical Record (PMR)}

When they want to write an assessment, it is difficult for employees to find the customer's PMR, so it takes quite a long time of about \pm 10 minutes to find a history of the previous PMR. This is because the preparation of PMR is still manual and when returning the PMR preparation tends to be tucked and reversed. The solution of this problem can create an electronic medical record system, so as to facilitate the search for customer PMR.

\section{Employee points check drug stock on stock cards}

Several times a customer looks for drugs with a particular product, the drug stock runs out. This is because employees tend to forget to write out goods in the consumables book. Also in charge of procurement of goods in this case is carried out by the PSA, often forgetting to order drugs, even though the employee has written in the book of goods out. If the goods run out, the employee will make sure by checking the stock card. This takes about \pm 4 minutes in the search for card stock. The solution to these problems is to create an inventory management system, and to create a reminder board and order items out.

Drug points completed, verification of customers again.

There are some employees who forget to verify the customer again. This is due to employees giving a long service time of about \pm 10 minutes, so that some customers experience a long queue buildup. Also caused by a rush of about \pm 5 minutes to verify identity, and there is no reminder that can tell how long the queue is, employees cannot predict the length of the queue at that time. The solution is to create a queue number card that customers can use when queuing.

\section{Payment points, drug delivery, counseling}

Several times customers do not pay for drug purchases, and when checking the price of drug takes a long time. This is because the employee forgets to verify the payment again, so the employee does not know the customer who has already made the payment for the drug or has not yet made the payment for the drug. The K pharmacy cashier system is still manually, checking the price takes quite a long time of about \pm 3 minutes, because it has to check the pricelist first. The solution is for payments to be made before the drug is prepared and customer verification and the creation of a cashier system. 


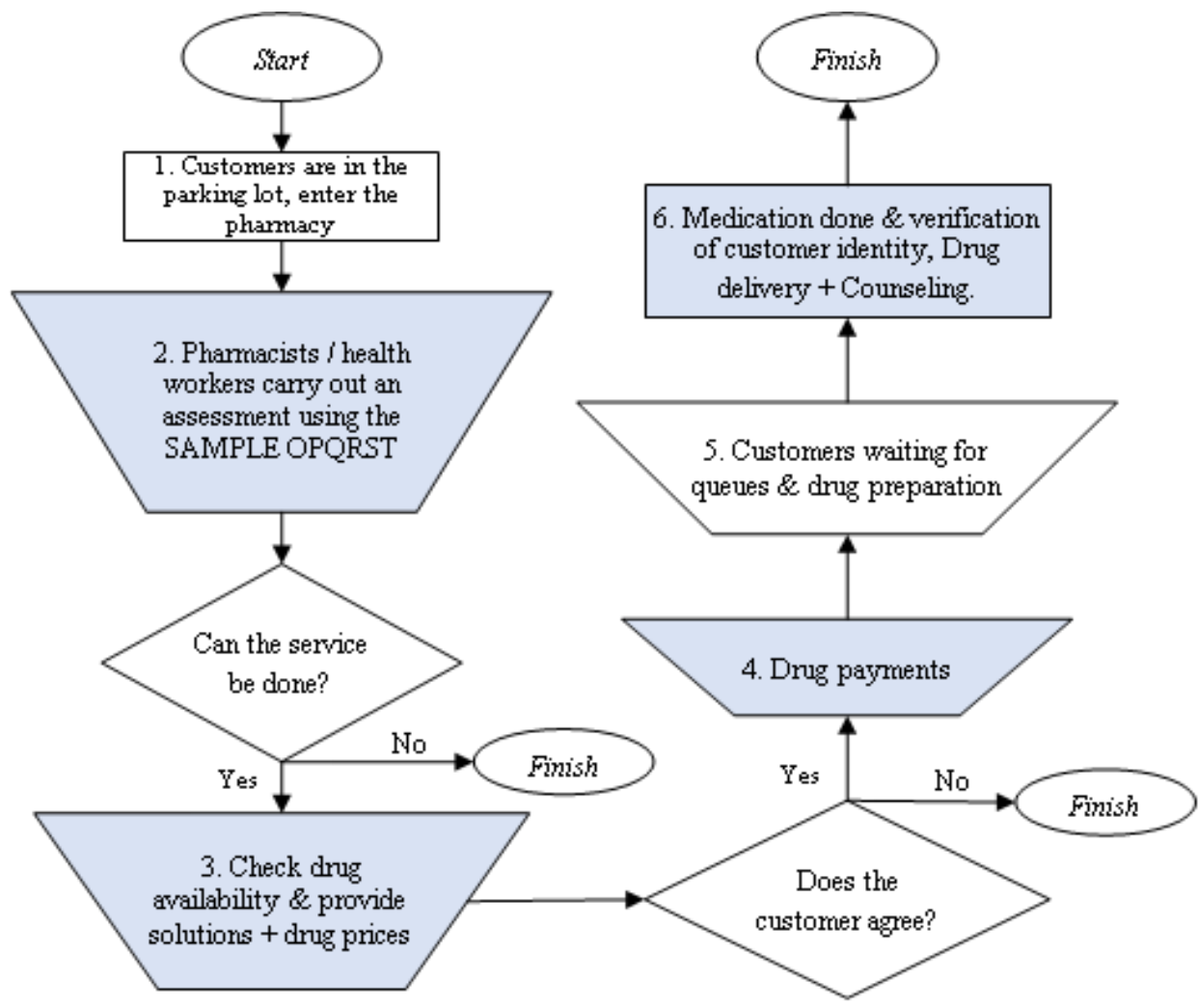

Picture 5. Flowchart for pharmaceutical / medical supplies without prescription after evaluation

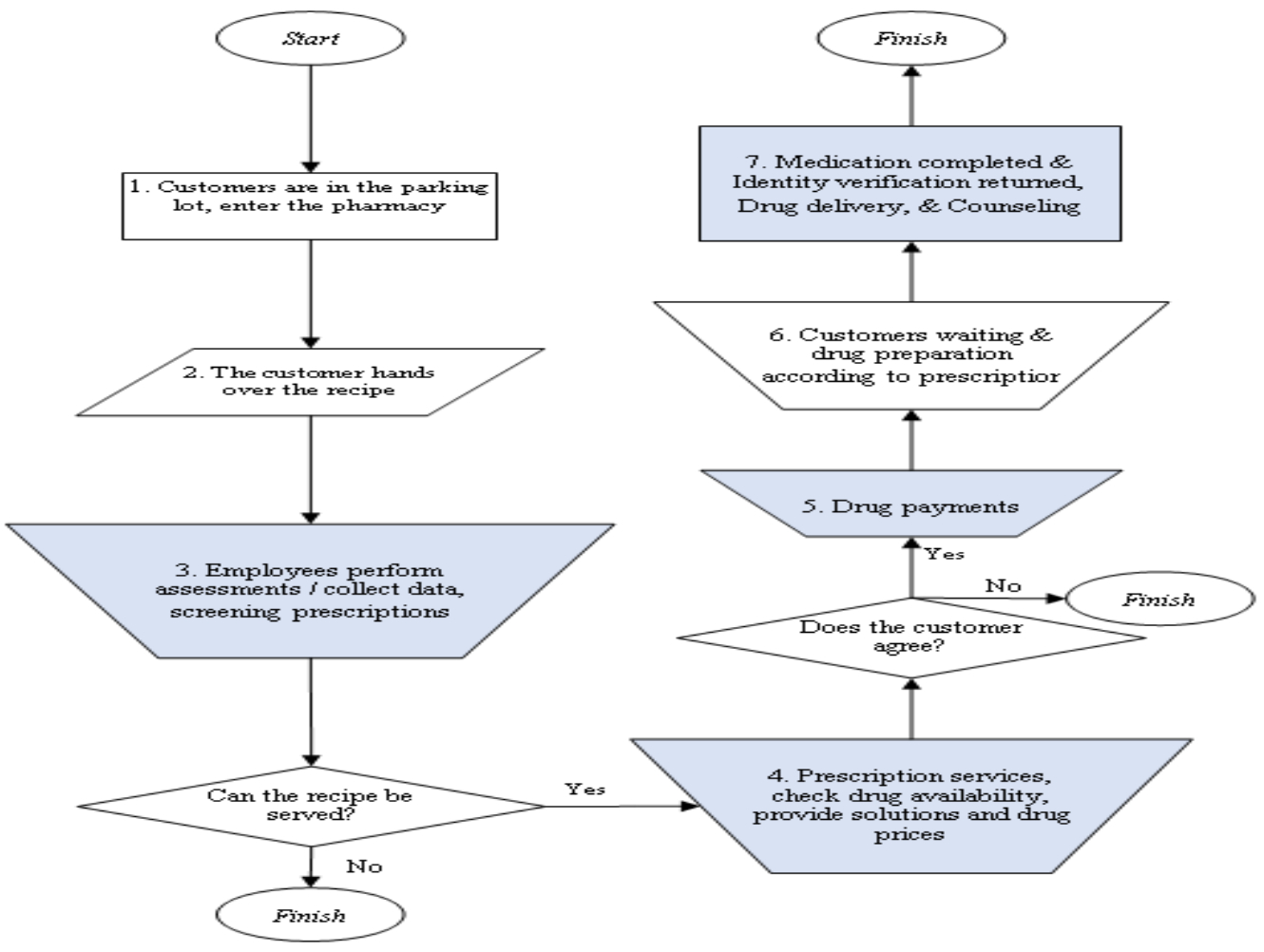

Picture 6. Flowchart for pharmaceutical / medical supplies with prescription after evaluation 


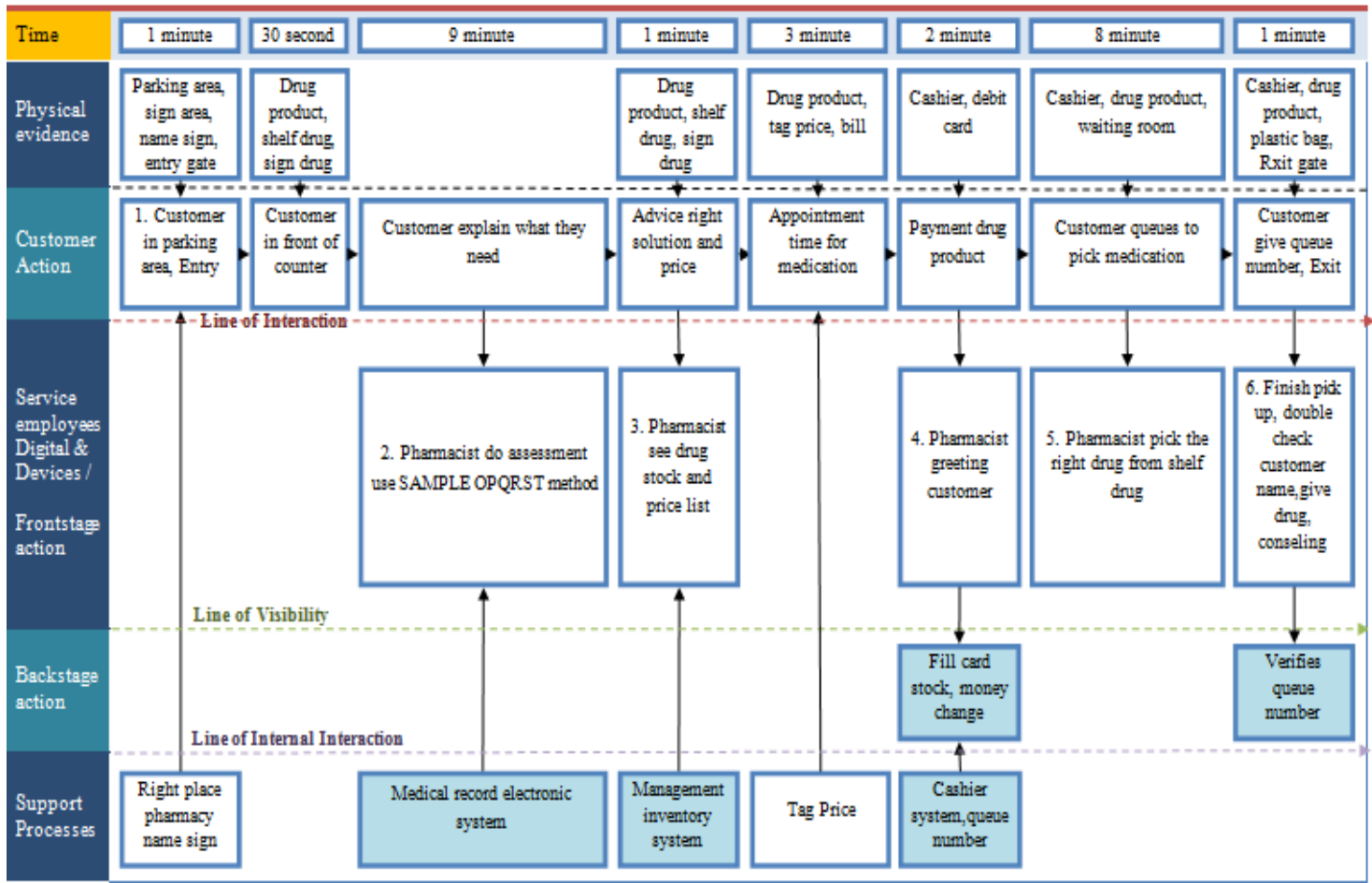

Picture 7. Service blueprint for pharmaceutical / medical supplies without prescription after evaluation

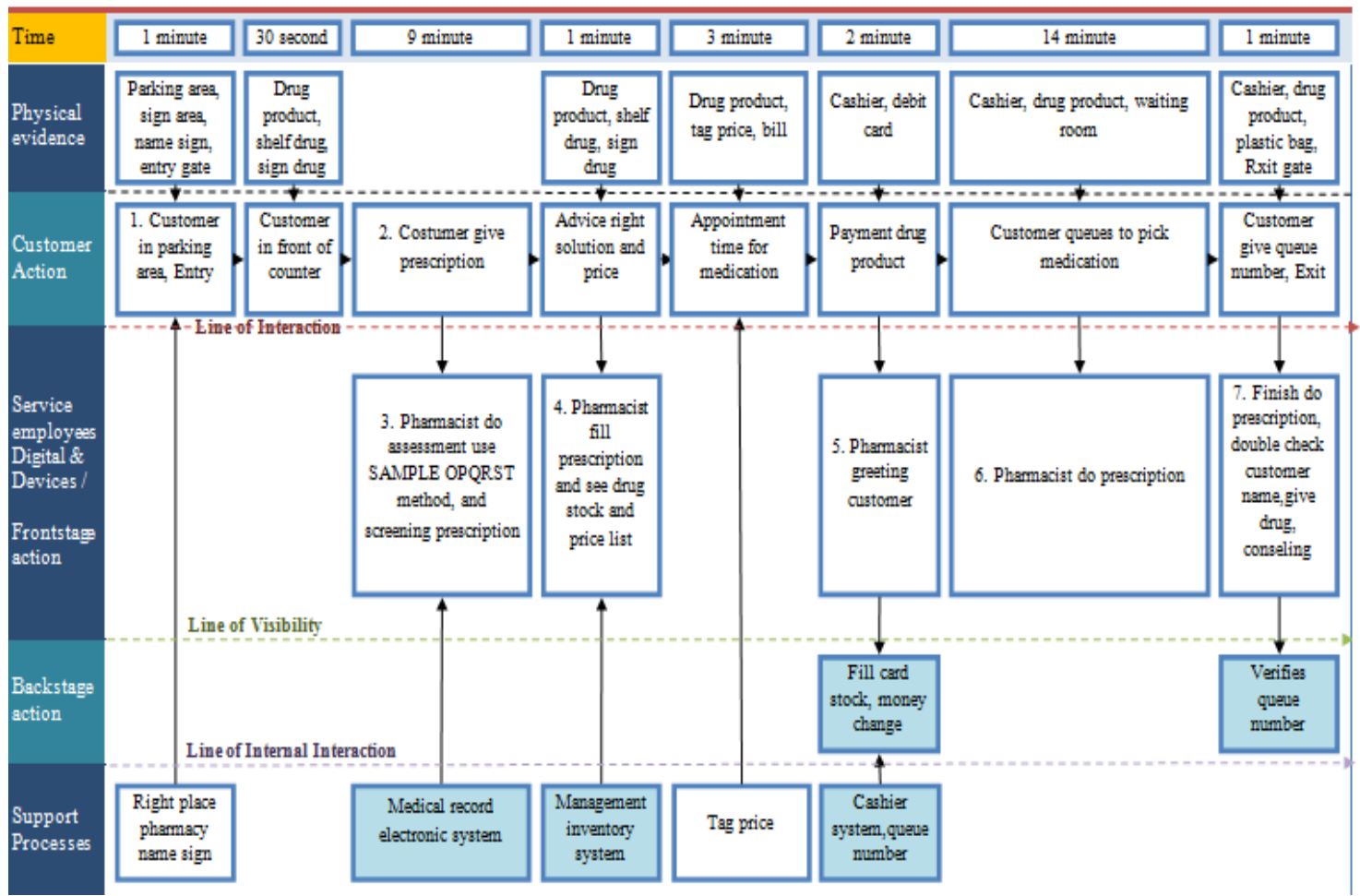

Picture 8. Service blueprint for pharmaceutical / medical supplies without prescription after evaluation

\section{Implementation}

Service blueprint improvement solution applications, which have been evaluated in the provision of clinical pharmacy services at the K pharmacy for 2 weeks from January 2-15, 2020. One of the solution points that can be applied to the existing procedure system at the K Pharmacy is: 


\section{Electronic Medical Record System (PMR)}

Hope with this electronic medical record system can facilitate the search for customer medical records. Use of Microsoft Office Word is used in PMR data processing. PMR data which is still manual is slowly being transferred to the system. PMR input is done when the customer needs counseling and is willing to do further assessment, both during working hours or outside working hours, in accordance with the agreement with the customer.

\section{Inventory management system}

Processing of checking drug stock / medical devices currently using the MOKA application. The advantage in using the MOKA application is that it can be connected directly to the cloud system, so reports can be obtained in real time right away. For processing inputting stock dashboard data can enter using Mozilla Firefox or Google Chrome, while for the cashier system or Point of Sale (POS) can use mobile payments specifically provided for pharmacy sales. It is expected that this system can make it easier to manage drug supplies / medical devices and clinical pharmacy services at the K Pharmacy.

\section{Customer Queue Number for Queue Verification}

At the product payment service point, customers will get a queue number after paying for drugs / medical devices first. After getting a queue number the customer can wait based on the queue number, then it will be called according to the queue number. When taking drugs / medical devices, the queue number can be returned back to the pharmacy.

\section{Electronic Cashier System}

Currently the K pharmacy uses the MOKA POS mobile payment application system, to reduce the risk of errors in ensuring drug payments to customers, and shorten service times. During the implementation of the service blueprint improvement solution, observations of non-prescription and prescription service time measurements were made at the $\mathrm{K}$ Pharmacy during January 2-15, 2020.

Observation of service time measurement after SPO application and service blueprint are in accordance with service standard. Non prescription service time after SPO application and service blueprint is around 20 minutes 27 seconds. This is in accordance with the service standard of less than 30 minutes. While the recipe service time after SPO application and service blueprint is around 32 minutes 38 seconds. This is in accordance with service standards of less than 60 minutes. It can be concluded that the application of SPO and service blueprint can affect the speed of service time delivery.

Offering several of these solutions, aims to improve existing systems and procedures, for effective and efficient performance. Application of the MOKA POS application is introduced to pharmacy employees and pharmacy facility owners. The owner K pharmacy is interested in running this solution.

\section{CONCLUSIONS}

This research has designed 12 flowcharts, 12 SOP and 2 service blueprint. K Pharmacy has several improvements about system procedural clinical pharmaceutical service using service blueprint method including: The point of employee writing an assessment in the patient medical record (PMR) and the solution is implement an electronic medical record system to make easier find customer PMR data. The point check drug stock on cards and the solution is implement inventory management system to find out minimum stock that must be available then order can be made. The point verification customer to take drug and the solution is provided customer queue serial number to verify delivery of drugs to right customer, this was made to reduce the risk of errors in the payment. The point payment, drug 
delivery and counseling and the solution is implement an electronic cash register system to shorten service time, payment of drugs / medical devices can be done before preparing drug.

This study has limitations. Sustainability training assistance is needed to use the inventory management application and the cashier system, so the use of that system does not stop at this research. Need to continue application the customer complaints box, inventory management system and cashier system, this can be continuous improvement of service at $\mathrm{K}$ Pharmacy. The owner needs listening employee complaints further. Recommendations for future research need to be investigated regarding the SOP for management pharmaceutical preparations, medical divide, which includes procurement, receipt, storage, destruction, control, and reporting.

\section{REFERENCES}

Berkley, B. J. 1996. "Analysing service blueprints using phase distributions". European Journal of Operational Research. Vol 88 (1), pp: 152-165.

Creswell, J. W. 2018. Research Design: Qualitative, Quantitative and Mixed Method Approaches 4th ed. SAGE Publications: London.

Fitzsimmons, J. A., M. J. Fitzsimmons \& S. Bordoloi. 2014. Service Management: Operations, Strategy, Information Technology 8th ed. Mc Graw Hill: New York.

Kementerian Kesehatan RI. 2011. Pedoman Cara Pelayanan Kefarmasian yang Baik $(C F P B)$. Kementerian Kesehatan RI: Jakarta.

Neuman, W. L. 2011. Social Research Methods: Qualitative and Quantitative Approaches 7th ed. Pearson: Boston.

Menteri Kesehatan RI. 2016. Peraturan Menteri Kesehatan RI Nomor 73/MENKES/PER/XII/2016 tentang Standar Pelayanan Kefarmasian di Apotek. Jakarta.

Menteri Kesehatan RI. 2017. Peraturan Menteri Kesehatan RI Nomor 09/MENKES/PER/I/2017 tentang Apotek. Jakarta.

Ross, I., L. C. Ruiz \& S. Samadzadeh. 2014. Service Blueprints: Laying the Foundation. [Online] Available: https://www.cooper.com/journal/2014/08/service-blueprints-layingthe-foundation. [April 20, 2019]

Sekaran, U. \& R. Bougie. 2016. Research Methods For Business: A Skill Building Approach 7ed. John Wiley \& Sons: United Kingdom.

Stickdorn, M. \& S. Jacob. 2011. This is Service Design Thinking: Basic-Tools-Cases. Amsterdam: BIS Publisher. 